Wings with opaque streak at distal third of costal margin, the ulnar area much expanded to the entire exclusion of the distal part of the discoidal. Anterior and middle femora of the $q$ slender, of the $\delta$ stout.

Genital segment of $\delta$ very like that of $D$. viridis; ovipositor of $q$ with the inferior tooth of the lower valves smaller than in viridis.

In color varying from light olivaceous green to dark greenish brown, with a dark brown stripe from hind margin of eyes along the sides of the pronotum, sometimes continued upon the humeral field of the tegmen. On the pronotum and head this stripe is usually about one-fourth the width of the side of the pronotum but sometimes becomes barely perceptible; it sometimes appears upon the disk as a narrow line just within the lateral carinae of the metazona.

Antenna. H. fem. Teg. Teg. $<$ H. fem. Body. Total length.

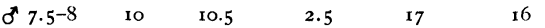

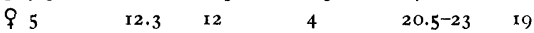

Described from $5 \delta, 2 q$ I ; $q$, Anglesea, N. J., labelled by Prof. L. Bruner, received from Prof. J. R. Smith. I $\delta$, I 9 , Ravenswood, L. I., Beutenmüller; I $\delta$, Ga. ; I $\delta$, Md. ; $2 \delta$ without locality; - all these latter from Mr. Scudder's collection.

This species agrees with the description of occidentalis in the form of the pronotum and disposition of the lateral carinae, but the median carina is not sufficiently elevated to be properly called subcristiform, and the vertex of the head is distinctly depressed behind the front margin, a character in which it differs markedly from the description of mystecus which occidentalis is stated to closely resemble. In superficial appearance the female recalls the short-winged form of Sten. curtipennis, from which it is readily distinguished by the absence of foveolae.

\section{NOTES ON THE OVIPOSITION OF} THANAOS ICELUS (?).

May 27, 1894, at Turkey Hill, Arlington, Mass., I noticed a species of Thanaos fluttering around a plant of Baptisia tinctoria as if to lay eggs, returning to the same plant several times and finally laying a single egg, in two seconds, upon the upper side of a young and tender leaf near the base. This occurred at one o'clock on a warm, sunny day. Three more eggs were found upon the same plant. By searching, a dozen more such eggs were found, one or two on each plant, nine on one plant, always single and on the upper surface of the leaf. Numerous eggs were found similarly on May 30 , also nests of a young Thanaos on Baptisia. June 3 , a long and careful search revealed abundant nests, but only a single egg, and the imagos had become rare. The eggs were pure white when laid, turning pink or orange within four hours; base flattened, sides littlerounded, summit depressed; longitudinal ribs ten, transverse ridges wide, prominent, quite concave; at micropyle a saucer-like depression with hexagonal margin; breadth of egg, $0.76 \mathrm{~mm}$.

Fustus W. Folsom.

Calephelis Borealis.- Looking over some miscellaneous entomological material the other day, which material had been captured by some of the students for the Station collection during the past summer, in this (Montgomery) County, I came across two unidentified specimens of Calephelis borealis. I closely questioned the student, but he could remember nothing as to date or immediate locality, or in fact anything, save that they had been caught near Blacksburg last summer. I note this, for while the butterfly has been taken in West Virginia by Mr. W. H. Edwards, I believe this is the first Virginia record, and any information concerning this species is desirable.

Blacksburg, Va., March 27, 1896.
Ellison A. Smyth, Fr. 

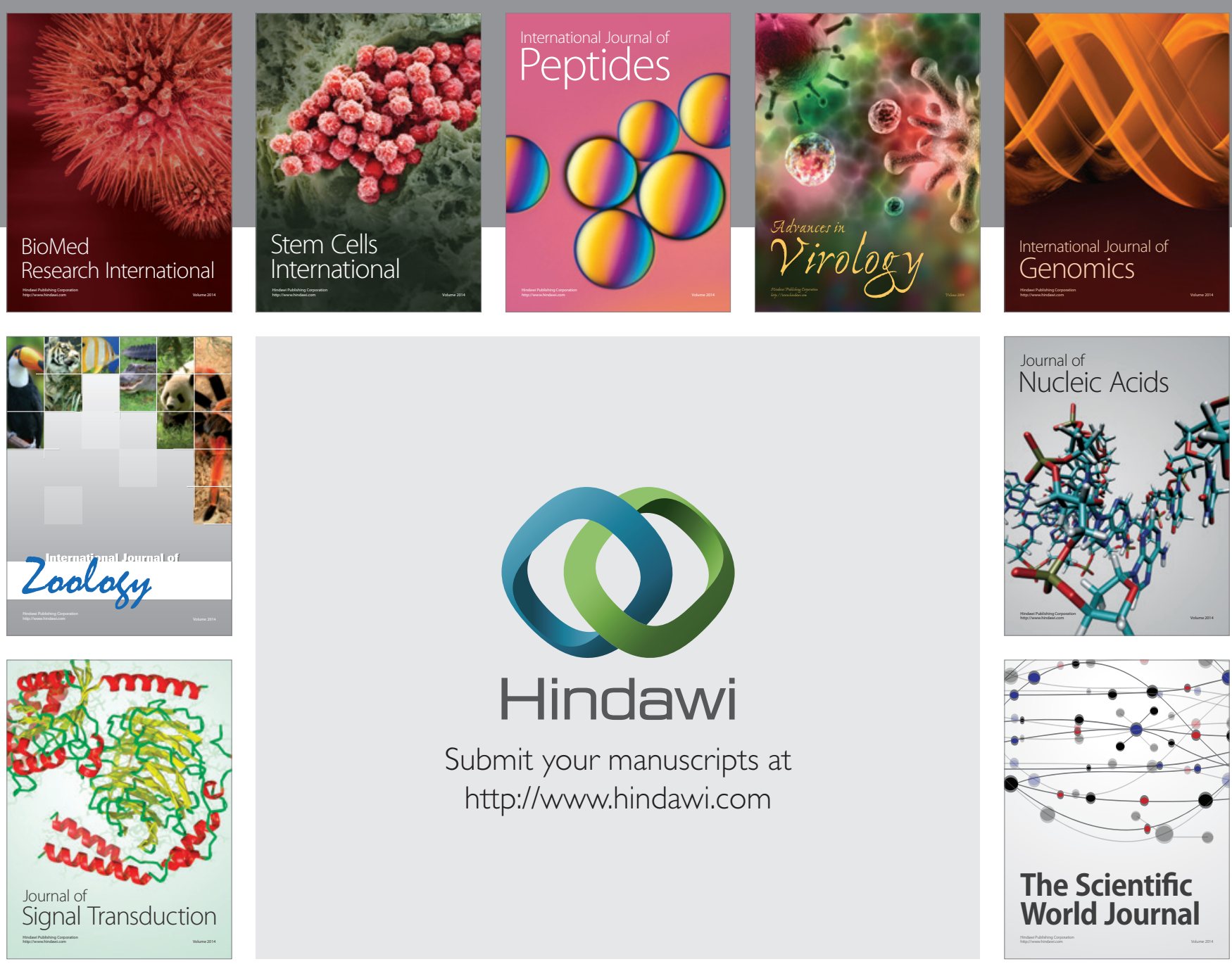

Submit your manuscripts at

http://www.hindawi.com
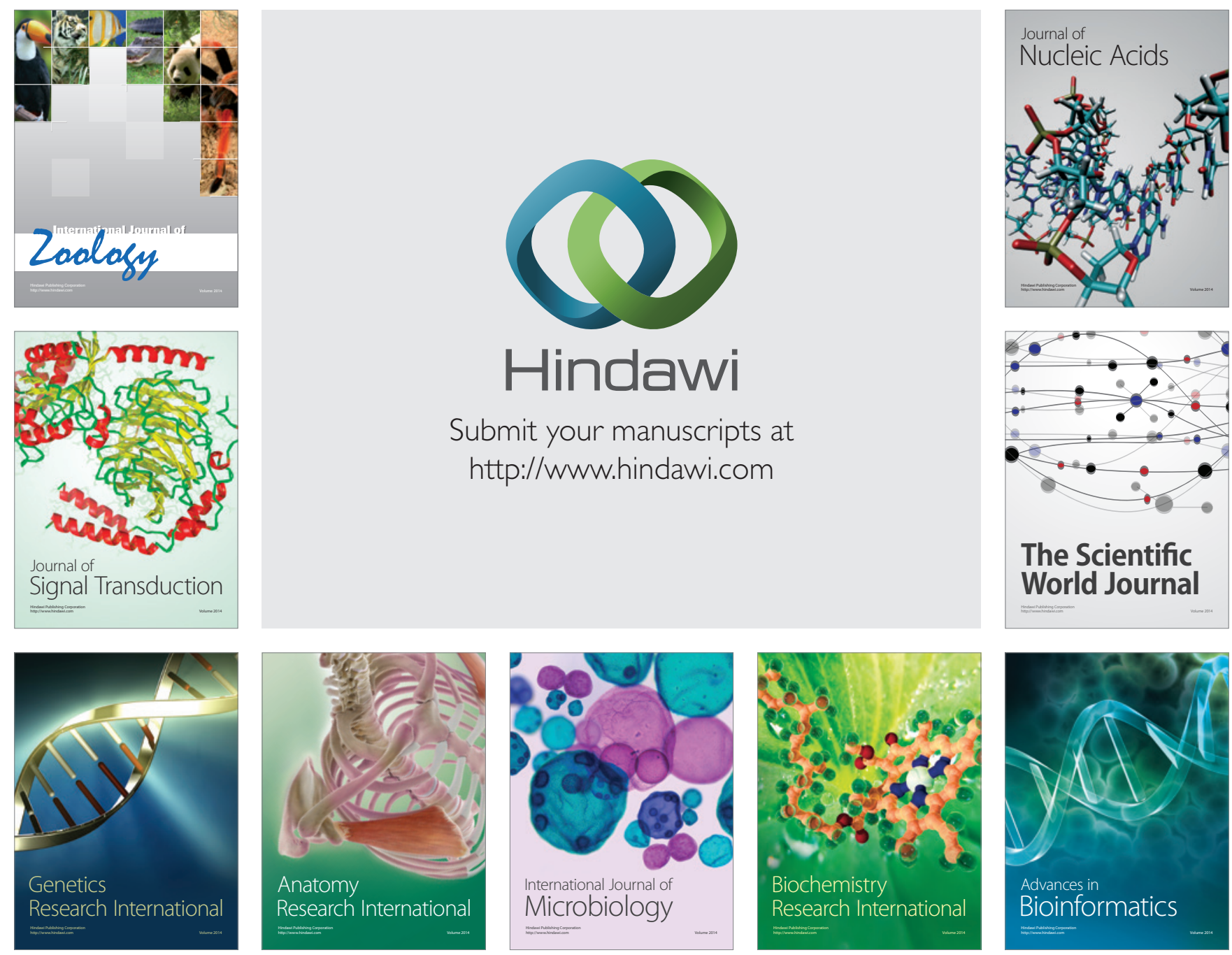

The Scientific World Journal
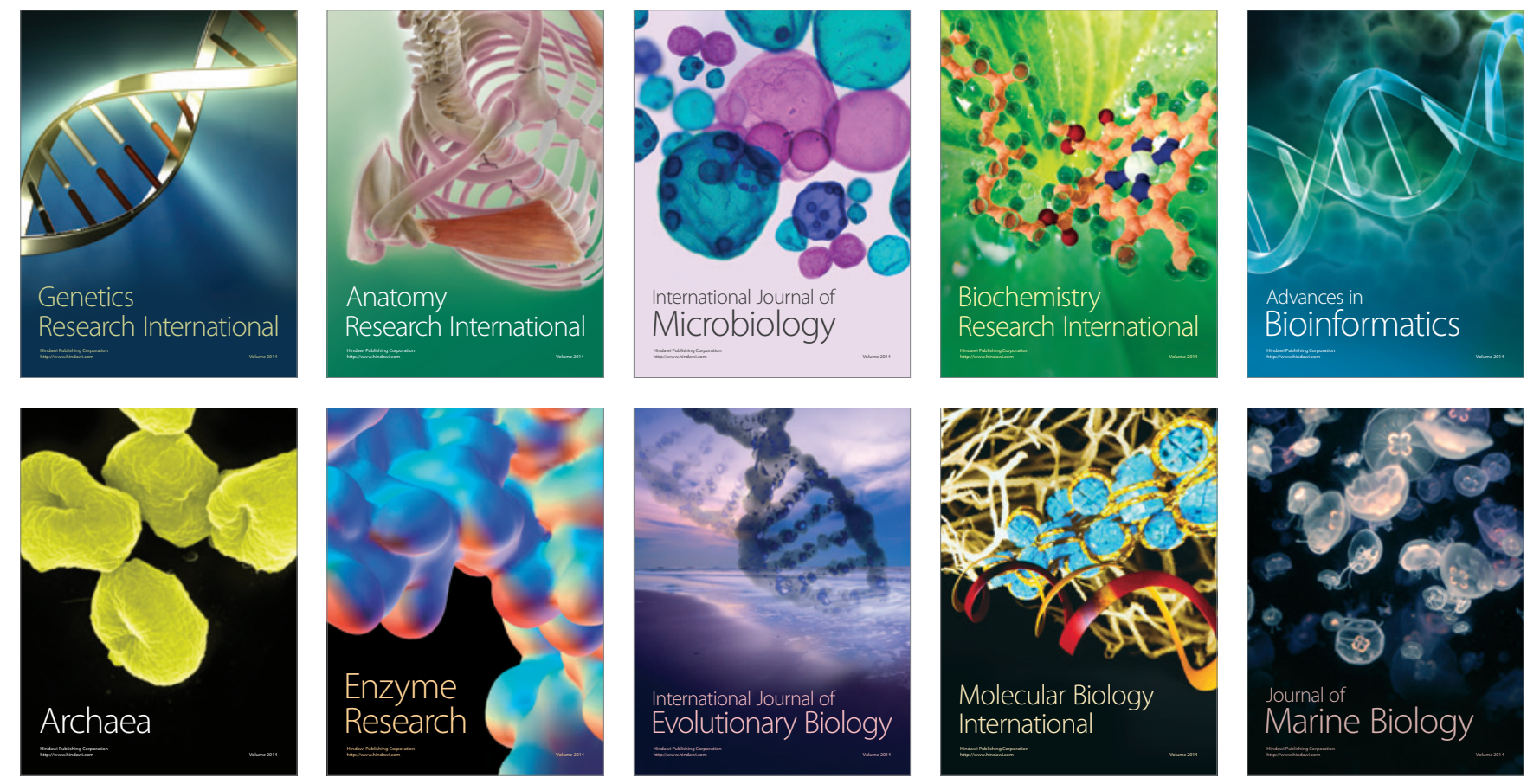